\title{
COVID-19 - Second liberation war of Bangladesh
}

\author{
Muhammad Torequl Islam
}

Department of Pharmacy, Bangabandhu Sheikh Mujibur Rahman Science and Technology University, Gopalganj (Dhaka)-8100, Bangladesh

DOI: $10.36348 /$ sjnhc.2020.v03i08.002 $\quad$ | Received: 30.07 .2020 | Accepted: 07.08 .2020 | Published: 09.08 .2020

*Corresponding author: Muhammad Torequl Islam

\section{Abstract}

Building strong resistance against the Covid-19 is now the major challenge around the world. Since there is no reliable remedy, many strategies have been adopted so far to get rid of it. It is already prevalent in a number of countries, but in most cases it has been made possible by lockdowns and adherence to unlimited hygiene as relaxation of these intitiatives causes re-infection. While the whole world is worried about Covid-19, Bangladesh, a South Asian country, is plagued by various dangers, which is causing a lot of frustration among the people of this country. Dengue, floods and waterlogging, indifference to human health and shaky government management are rampant in this country. However, it is only a matter of time before a strong fight is waged against Covid-19, as the country looks to the world for a vaccine, which is deteriorating overall situation. In this article, some of the things to do in the world like Bangladesh and this country have been highlighted.

Keywords: SARS-CoV-2; Covid-19; Medical service.

Copyright @ 2020: This is an open-access article distributed under the terms of the Creative Commons Attribution license which permits unrestricted use, distribution, and reproduction in any medium for non-commercial use (NonCommercial, or CC-BY-NC) provided the original author and source are credited.

\section{INTRODUCTION}

The severe acute respiratory syndrome coronavirus 2 (SARS-CoV-2) already appearing in the form of a pandemic has given rise to various fears within us, for example- Is it the most chronic epidemic! How long it will last! How many more peoples will we lose! Will I get the appropriate treatment or vaccine! Everyone will be able to return to work as before! We seem to find ourselves in a great economic, social and medical uncertainty. The impact of this pandemic is even greater in the context of Bangladesh, since the public life, economic, and health management of this country is fragile in nature. The country is a hotbed of mismanagement and corruption from all sides. In the meantime, the country has to deal with a catastrophic cyclone 'Amphan'. Now is the rainy season, the time of the dengue virus outbreak. The impact of the dengue outbreak in 2018-2019 was noticeable, especially in 2019, the country lost thousands of lives. Several dengue cases have been already found. Meanwhile, many areas, including the country's capital, have been flooded. It is the optimum time to maintaining social or personal distance in accordance with hygiene rules or staying in the home quarantine, but the homes of millions of people are underwater! These waterlogged people live an agricultural life, whose workplaces are now completely under water. There is no limit to the suffering of those who make a living by raising animals, since they can't feed or sell their animals. Basically, they need food, shelter, drinking water, and hygienic facilities more than just to fight against the novel coronavirus disease 2019 (Covid-19). Unfortunately, from the very beginning, the various steps taken by the central government in the pandemic were uncoordinated, at a time when the crisis is getting worse.

When the overall situation has reached such a stage, it has been associated with corruption in various coronary and non-coronary medical sectors, which are not desirable at all. Compared to other countries in the world and even in South Asia, the daily corona patient test rate in Bangladesh is negligible, making difficulty in understanding the infection peak and taking action accordingly. What is happening is also a combination of incoherence, dishonesty, the power to make people angry. The number of health care providers, physicians, and health workers is very small, which is quite noticeable. The pandemic situation has not been closely monitored by the administration from the beginning. Foreign workers are an important source of income in this densely populated country, helping their family members to move on. Many foreign workers are losing their jobs due to the pandemic, which could affect the country's economic downturn in the future. A large part of the population may be going through a famine. 
It is very important for a poor state to keep the wheel of the economy moving in any way. The overall situation begs the question - what exactly are we going to do now? Will we continue to move slowly or will we continue to do so at least until a good medicine or vaccine comes out? Trials are currently underway on 165 vaccines, of which 26 are in human trials worldwide. Bangladesh has participated in the only vaccine trial under the auspices of which no state response has been received so far. Researchers are embarrassed by this kind of behavior, so people do not get a chance to understand the essence of research, which is the opposite of advancing research. There is no substitute for research to ensure the growth, equitable distribution and well-planned use of a country's resources. The institutions of higher learning in this country have not become a research-oriented either, the next generation may become even more unfortunate. Like many countries in the world, Bangladesh is looking at the Oxford University vaccine. Although, it has has received a promising response, but it remains to be seen how the rest will fare. Not expecting, if it somehow disappoints us, it would be only a matter of time before we know which way to turn. Meanwhile, vaccine advances have slowed drug research!

To date, doctors age generously treating patients with some drugs, including chloroquine, hydroxychloroquine, chloroquine phosphate, azithromycin, lopinavir-ritonavir, interleukin-6 inhibitors, favipiravir and dexamethasone. Although these are not specific therapies for coronaviruses, including SARS-CoV-2 and there is no scientific evidence behind them that they can reduce mortality among Covid-19 patients. Physicians have not adopted any controlled, approved or specific approach in this regard. Some people's lives may be saved, but in the near future due to irrational treatment, there may be a detailed misery. The failure of these drugs is also affecting drug research progress in Covid-19. The largescale vaccine trials could open the door to possibilities for an ideal vaccine, but the long line of vaccines will create an economic crisis for the impending epidemic.

We still have a lot of information about this airborne cytopathic virus, although regular research continues. SARS-CoV-2 has a higher mutation rate due to its RNA strand and larger genome size (32 kb); which is capable of acting as a host for many foreign genes. Reiter et al. reported that viral mobile genetic elements can integrate into the host chromosome through site-specific recombination within perfect homology between the short region of the host chromosome and the viral genetic material [1]. According to the recent research data of Bangladesh Council of Scientific and Industrial Research (BCSIR) of Bangladesh, there have been several mutations in Bangladesh till date with some changes in its spike (S) protein, therefore, it is destroying many beneficial bacteria in our body, resulting diseases like- diarrhea, dysentery, and so on. However, the prevalence of such diseases has increased in the waterlogged areas of the country recently. The RNA viruses can cause mutations in a variety of genomic and non-genomic ways, including surface protein-host interaction, viral replication and proofreading system, genomic alteration, lysosomal activities, recombination, conditional, complementation and benign relationship approach [2].

A virus undergoing co-evolution with the host over a long period of time, may develop a benign relationship, in this period it will not cause any disease to its host. However, after crossing from its natural host, it may cause diseases. For an example, Simian Immunodeficiency Virus (SIV) strains developed benign in their natural simian hosts, however, when they crossed from its natural host-sooty mangabeysinto macaques (a novel host), it caused an acquired immunodeficiency syndrome (AIDS) syndrome [3]. The genome sequence of the SARS-CoV-2 is found in $8-93 \%$ similar to the previous SARS-CoV.

We have to come up with a way out without dragging the uncertainty into a hurdle and continue to make every effort to implement it. If that fails, another approach can be taken. Uncertainties must be taken logically, should be positive, must keep faith. We have to be careful of the random negative things that are happening with us. It should be remembered that none of us was prepared or trained for this sudden pandemic. Our beliefs were that we were able to diagnose and treat accordingly, but the SARS-CoV-2 is really like a magnifying glass that sometimes shows depth like a microscope and sometimes as large as a telescope, has been able to show that we are still far behind. It has been able to show all the movements of the world at a glance.

Basically, we should maintain a healthy skepticism in order to save lives. The experiences of those who have already recovered from the Covid-19 should be shared more and more. Journalists can use the power of their stories to connect with readers so that they can have a sense of courage. In this way, not only the general public, but also doctors, pharmaceutical researchers and other health workers will get the decisions to take effective steps. Due to epidemics, physicians may suffer from skilled knowledge and rely on their own limited experience rather than scientific investigations. In addition to the different ethnic groups that have cured from the Covid-19, there is also a special need for same ethnic group's information; physicians will get a suitable platform to share their experiences. Adequate statistical evidence should be gathered about any complex decision; theoretical therapeutic techniques create suspicion - the success of appropriate treatment is hampered. 
Negative interventions on various trials that may cause harm should be transparently considered. It is best to keep the outcomes of the trials open to an experienced board so that we can meet the standards required to reach a reasonable conclusion, therefore, designed research approach should be considered. We are now passing through a time of uncertainty-related anxiety. In this way, the morality of the superiors should be established by understanding the mental condition of those who are returning to work even in a short range. It is very important to provide emotional encouragement to those who are already affected or bored and to bring back those who are biased in this regard to purity. Issues that may increase health risks should also be clarified, so that hygienic conditions do not deteriorate.

Drugs used on the basis of case reports in the advancement of pharmacology may be able to disable our fight against future recurrences of the coronaviruses. In this case, it is not uncommon for different medical approaches and drugs to come up with it, it may come up with a better drug or method. But in no way is it desirable to hide medical results; this will further increase the number of accidents. Without a prescription, many may become accustomed to such drugs, which will put a new burden on a poor country like ours to overcome medical malpractice in the future. Furthermore, the intense desire to seek remedies by adopting new, unproven management can hinder healthcare providers from providing quality medical care to patients. The foundation of therapeutic management must be solid and rational.

Neglecting the responsibilities of physicians and health workers is not at all desirable at this time, they need to be more careful; they also need to ensure the necessary facilities from the administration.
Consultative discussions should be held with the patient at least ensure the criteria and success of the clinical trials. The main thing is not to delay or suspend the overall process on the basis of exclusion just to get out. Unfortunately, the suffering of non-Covid-19 patients has also increased immensely. Added to this row is the looters of epidemic benefits (epidemic capitalist people). Sensitive responses need to be made more understandable; if we want to carry out our responsibilities effectively, we must at least keep alive the hope of co-operation.

We are basically going through an unknown future catastrophe, however, besides the doctors we have another beacon of hope is the pharmaceutical industry. This sector needs to be further developed and every effort needs to be made to take it forward in an advanced manner with medical science. Criticisms need to influence thought processes by supporting reasoning. In a word, beyond mistakes, incoherence, irrationality, neglect and immorality; we must now act in a fast but careful and reliable way with caution and logic.

Conflict of Interest: None declared.

\section{REFERENCES}

1. Reiter, W. D., Palm, P., \& Yeats, S. (1989). Transfer RNA genes frequently serve as integration sites for prokaryotic genetic elements. Nucleic Acids Res. 17:1907-1914.

2. Sanjuan, R., \& Domingo-Calap, P. (2016). Mechanisms of viral mutation. Cell Mol Life Sci. 73:4433-4448.

3. Stern, A., \& Andino, R. (2016). Viral Evolution: It Is All About Mutations. Viral Pathog (Third Edition). 233-40. 